\title{
A COMPUTERISED SYSTEM FOR FEATURES IMAGE DISPLAY AND IDENTIFICATION OF WOODS FROM CHINA
}

\author{
by \\ Yang Jiaju and Cheng Fang \\ Research Institute of Wood Industry, Chinese Academy of Forestry (CRIWI), Wan Shou Shan, \\ Beijing, People's Republic of China
}

A computerised system WIP89 (Wood Identification Program 1989) for wood identification, tree species index and image display of wood anatomical features has been developed. In total 669 species, mostly Chinese woods, including 500 hardwoods and 169 sofwoods, using 47 and 43 multistate characters respectively, and 27 images concerning 50 anatomical features have been stored in microcomputer file for identification and display.

The system uses a SUN 386-24 microcomputer with $2 \mathrm{M}$ byte RAM and $40 \mathrm{M}$ byte fixed disk, equiped with a high resolution colour CRT $(640 \times 350)$ for image display. The software consists of a main program (WIP89) for wood identification and image display and several utility programs for maintaining and creating databases. All the programs are written in Turbo Pascal (Borland International, 1987) version 4.0, which can be run on all IBM PC microcomputers and its compatibles. The menu-driven modification is user friendly. The response time for searching species is less than one second.

The main functions of the system are:

1. Search of species from characters. Based on the input of characters from the unknown, the system searches the database and finds specific matching species. There is no limitation to the number of characters at one time!

2. Search of species after input of the first letters of family, genus or species (specific epithet).

3. Demonstrate the on-line character-code list for guiding those users who are not familiar with the character codes. This system uses only multistate characters.

4. Modify, display and print the contents of the species databases. There are two databases: on softwoods and on hardwoods. Each database has several datafiles including tree name files, character files, coding-list files, image files, etc.

5. Feature Image Display. This is a new tool in computer-aided wood identification. To realise this function, the wood feature image is converted to the data file with an image scanner; then the image on the computer screen is optimised. The image is displayed with a $300 \times 300$ point matrix with 16 colours.

The system is available from CRIWI for exchange or purchase. 